\title{
Spinal Cord Injury in a Former Gang Member: Using an Existential and Strengths-Based Approach
}

\author{
Larry D Williams ${ }^{1 *}$, Sarah Dewitt-Feldman ${ }^{2}$ and Flavia Avanci ${ }^{3}$ \\ Department of Social Work, North Carolina Central University, USA \\ Master of Social Work Department, North Carolina Central University, USA \\ Brazilian Army Enlistment Department, USA
}

Correspondence should be addressed to Larry D Williams, 1dwilliams@ nccu.edu

Received: May 16, 2020; Accepted: May 28, 2020; Published: June 04, 2020

\begin{abstract}
This case study will explore the use of an existentialist psychotherapeutic lens used by a clinical social worker with a former gang member who sustained a paralyzing spinal cord injury. For this client, his injury provided a turning point that prompted him to reevaluate the meaning in his life, and he was able to find new meaning through relationships. Many of this individual's former gang associates provided direct care to him following the spinal cord injury he sustained and went on to receive medical training.
\end{abstract}

\section{KEYWORDS}

Strengths perspective; Resilience; Existentialism; Gang affiliation, Spinal cord injury; COVID-19

\section{INTRODUCTION}

The existentialist therapeutic model involves focusing on a client's search for meaning in their life. A significant event such as an injury or the onset of a disability, or another significant change, can cause a reevaluation of meaning and life. The client in this case study sustained a severe spinal cord injury: The injury he sustained in the cervical spine region-specifically, in the area of the $\mathrm{C} 4$ cervical vertebrae-rendered him completely paralyzed from the neck down. This injury was sustained from a gunshot wound inflicted by the client's brother. Following the injury, the client was not approved for around-the-clock medical care, and many of his former gang associates provided direct care to him in shifts. The

client sought out counseling in the hopes of finding new meaning in life-his previous activities and significant aspects of his previous identities were no longer accessible to him. This study will explore the role of existentialist therapies and the strengths-based perspective, the location of meaning in the client's life, and the role of the relationship between the client and his associates and the community.

\section{PHYSIOLOGY}

Spinal cord injuries (SCIs) occur when the spinal cord is bruised, torn, or, rarely, severed, which typically takes place due to physical trauma [1]. SCIs are categorized depending on location and level of injury; cervical spinal

Citation: Larry D Williams, Spinal Cord Injury in a Former Gang Member: Using an Existential and Strengths-Based Approach. J Clin Cases Rep 4(4): 110-115.

2582-0435/@ 2021 The Authors. Published by TRIDHA Scholars. 
cord injuries take place in the neck region, where there are seven cervical vertebrae, C1-C7, and eighth cervical nerves, C1-C8 [2]. Spinal cord injuries can cause loss of sensory and motor control at and below the site of injury, meaning that cervical spinal cord injuries can cause tetraplegia-paralysis or weakness in both arms, both legs, and chest-which is categorized as complete tetraplegia if there is no movement or feeling [2]. Spinal cord injuries are considered "complete" when they result in all loss of motor and sensory function below the point of injury [3].

\section{PROGNOSIS}

Spinal cord injuries are a leading cause of paralysis in the United States [4]. Complete paralysis resulting from SCI has a less than $5 \%$ recovery rate, which drops close to zero after 72 hours [5]. Individuals with SCI have much shorter life expectancies than the general population, with an especially high mortality rate during the first year after injury [6]. For individuals who survive 24 hours after a spinal cord injury, with any level of injury that requires a ventilator, the average life expectancy following injury ranges from 3.7 years - 11.2 years, depending on age at the time of injury [6]. The presence of breathing difficulties in the case of an SCI suggests that the injury is severe, and assisted respiration is needed by about one-third of cervical SCI patients [1].

Mortality rates among Black Americans with SCIs are slightly higher than those among whites with SCIs, and mortality rates among those whose SCI resulted from violence are higher than those among individuals who sustained SCIs in car crashes [7]. One study found that during the twelve years following a spinal cord injury, suicide is the leading cause of death for individuals whose injury resulted in complete paralysis [8]. While substantial progress has been made over the last several decades in reducing mortality during the first year following a spinal cord injury, not nearly as much progress has been made in reducing mortality for the subsequent years [7]. Causes of death in individuals with
SCI are generally acute in nature-like infection and injury-while causes of death in the general population are generally chronic diseases [7].

\section{PREVALENCE}

Spinal cord injury prevalence in the United States is higher than in European countries, potentially due in part to higher rates of violence [7]. A study tracking spinal cord injuries between the years 1993 and 2012 found that while the prevalence of injury has remained stable in the United States, total occurrences have increased to reflect a growing population, with the most significant increase in SCI occurring in elderly populations [8]. New spinal cord injuries are estimated to occur in approximately 54 per one million people per year, and the overall number of individuals living with spinal cord injuries in the US is estimated to be 291,000 [6].

Violence, which includes stab wounds and, most frequently, gunshot wounds, accounts for more than $13 \%$ of spinal cord injuries [3]. Within the United States, the percent of SCIs attributable to acts of violence reached its peak in the 1990 s, when violence accounted for $21 \%$ of all spinal cord injuries [7]. In the past decade, spinal cord injuries in Black Americans have occurred at disproportionately high rates, and the overwhelming majority of new spinal cord injuries occur in males, according to data from the University of Alabama at Birmingham [10].

\section{QUALITY OF LIFE}

Individuals suffering from SCI are more likely than the general population to suffer from a mental health disorder. However, individuals with complete tetraplegia are significantly less likely than others with SCI to suffer psychopathology [11]. The higher up an SCI occurs on the spinal cord, the more breathing-related difficulties can occur, requiring individuals with SCI to use ventilators to assist respiration [12]. The healthcare costs and living expenses for an individual with complete 
tetraplegia are estimated to be $\$ 1,129,302$ the first year, and \$196,107 each subsequent year in 2018 dollars [6]. While $66 \%$ of individuals are employed at the time of injury, only $17 \%$ of those with SCI are employed one year after injury [6].

A recent study found that mobility is among the strongest predictors of quality of life in individuals living with SCI [13]. However, many providers who treat individuals with SCI do not examine the use of assistive devices when assessing outcomes [14]. Social support generally correlates to the quality of life in individuals living with SCI [15]. In individuals with physical disabilities in general, both social relationships and a sense of meaning contribute to the overall quality of life [16].

\section{PSYCHOLOGY}

Research sampling individuals with disabilities, including those with tetraplegia and paraplegia, has demonstrated a correlation between a sense of meaning in life and positive adaptation to physical disability as well as psychological wellbeing [17].

Existential philosophies can be employed to support individuals with disabilities in finding meaning and internal motivation following severe injury [18]. Frankl (1967) [19] highlights both the importance of a search for meaning and the relationship between clinician and client in the use of existential philosophy and logotherapy. Arvig (2006) [20] highlights the importance of relationships as a source of meaning for individuals with disabilities. A recent study found that among individuals with SCI, regardless of the severity of the injury, social support is among several predictors of hope, and a strengths-based perspective can be useful in achieving optimal rehabilitation [21].

\section{METHODS/METHODOLOGY}

The data-gathering phase was divided into three phases during six months of intensive counseling sessions with
LB. We met in: (1) the pre-counseling phase, (2) the counseling phase, and (3) the termination phase. The precounseling phase involved exchange of necessary information, establishing ground rules as a prelude to the therapeutic relationship, discussing issues of confidentiality, covering the basics of establishing a therapeutic relationship built on trust, and exploring any areas of conflict of interest. The counseling phase involved utilizing the strengths perspective as an alternative to the more common pathology-oriented approach to helping clients. Instead of focusing on LB'S deficits, the strengths model placed greater emphasis on his abilities, talents, and resources [22]. I employed an existential perspective to help LB find meaning and reconceptualize the meaning of his current life circumstances. Frankl explains that people who are able to find meaning in their productive inner lives have better chances not only of surviving adverse situations but of lessening the damage to their inner selves. The ability to process with the client was contingent on my ability gain his trust and build rapport. The absence of trust or the inability to establish trust shapes the context of the counselor-client relationship. In order to achieve therapeutic goals, LB needed to develop a level of comfort in order to divulge meaningful information that had to potential to either transform or hinder his current circumstances. The issue of trust is the cornerstone in two of Erickson's model of life cycle development [23].

\section{RESULTS}

During six months of intensive in-home therapy, I was able to help LB develop coping and problem-solving skills in three critical areas to help him effectively the multiple challenges faced by persons with spinal cord injuries. These include service delivery, developing trust, and finding meaning in his life circumstances.

First, the task involved developing a plan to address the gap in service delivery. I was able to link LB with community-based social service agencies that assisted 
him in obtain housing services, food, and utility services. However, LB's most pressing need was to obtain primary medical care and in-home medical services. LB spent most of his life in out-of-home placements and aged out of foster care at age eighteen, immediately joining a youth gang. He had no intact support system as both of his biological parents were incarcerated at the time of his injury and he was estranged from his maternal grandmother, who was his primary caregiver. The only available option for him was to obtain medical care from Medicaid. However, Medicaid was never designed to serve all the needs of everyone who is poor, nor address all the medical needs of eligible recipients. LB needed intensive-in home services, including skilled nursing. The provisions offered by Medicaid were restricted to categorical groups and income levels defined by the federal poverty guidelines. LB was limited to only twelve reimbursed hours per day of in-home care, which fell short of the twenty-four-hour care that was needed to address wound care, food preparation, and continuous monitoring of life support systems. In partnership with LB, a collaborative effort was formed between LB, gang members and community volunteers. Three shifts were established in which the gang members responsible worked in eight-hour increments, and community volunteers worked in four-hour increments. All volunteers received basic training in wound care, meal preparation, basic CPR, and effectively monitoring life support systems.

The Second phase involved building greater trust and rapport in the therapeutic relationship. I discussed at length the boundaries and guidelines of a therapeutic relationship. I explained the rules of confidentiality, including the possible risks of no confidentiality, such as the inclusion of information in my summary report. For example, information that may have infringed on the rights of others or presented a clear and present danger to identified individuals or the community would be an exception to confidentiality. During the course of the counseling sessions, LB made it clear that his gang affiliation primarily involved the sale and use of drugs. Although he had periods of prison incarceration, it was exclusively related to drug usage and sale. The therapist/client relationship improved. I established a therapeutic space undergirded by trust, mutual respect, autonomy, and freedom to define his goals and to make sense of his life experience

The third phase utilized the strengths perspective and existential approach to help LB gain more significant meaning and focused on the positive qualities of his situation. I made it clear to LB that the focus of this phase of the intervention involved a partnership in which we would work jointly to define his goals. Initially, LB focused on his dysfunctional family relationships and his experiences in foster care. I validated and acknowledged his lived experiences and emphasized that he had the option to explore his talents, skills, and choices in forging a new self-concept and identity. He explored areas that presented opportunities, including forging an alliance with his community and redirecting pathological behaviors of gang members. Before therapy, LB's identity and self-concept were defined exclusively by his role as a leader of a youth gang. The spinal cord injury eviscerated his identity and created an existential vacuum that caused intense emotional pain and suffering. The amalgamation of the strengths perspective and existential therapy formed the basis for LB to take responsibility for his choices. These decisions positioned him to define the meaning and the choices he needed to make to close the existential void.

According to Frankl [24], at various points, life will impose challenges for us to solve. In response, we often "what is the meaning of my life?" However, frankly believes that we should not ask for the meaning of our existence. Instead, we should answer the question asked by a universal cosmic authority to define the meaning of our life. It is the moral equivalent of Kant's categorical 
imperative, which posits we should not ask, but rather what we must answer and do what we must do.

\section{CONCLUSION}

This case study underscored the importance of using strengths-based and existential therapy as an intervention with individuals with severe spinal cord injury. Throughout his twenty-two years of living, including years in foster care, gang membership, parents who spent most of their adult life incarcerated in prison and being shot by his brother in an altercation that left him paralyzed from the neck down. He faced what seemingly were insurmountable challenges, but he did not let his circumstances define his life. Instead, he was able to form a partnership with gang members and his community to provide compassionate and effective health care that kept him alive for a year. Sadly, LB's life was cut short by respiratory failure. I attended LB's funeral, and it was standing room only. I head tribute to is legacy, including community leaders, former gang members who now considered carriers in allied health, and other professions. LB's brother, who shot him, was granted permission from the prison authorities to attend LB's funeral. It is essential to mention that LB refused to testify against his brother in court, and multiple times before his passing petitioned the District attorney to drop charges all charges. According to Frankl [24], "each man is questioned by life; and he can only answer to life by answering to his own life; to the life, he can only respond by being responsible" p172). The world is facing COVID-19 pandemic, which is causing incalculable health, economic, and existential challenges. I hoped that LB's response to his circumstances would serve as an example for many follow.

\section{REFERENCES}

1. National Institute of Neurological Disorders and Stroke (2019) Spinal cord injury information.

2. University of Wisconsin Healthwise (2019) Classification of spinal cord injuries.

3. Mayo Clinic (2019) Spinal cord injury.

4. Administration for Community Living (2016) CDC research finds spinal cord injury is a leading cause of paralysis in the United States.

5. Chin LS (2018) Spinal cord injuries: Prognosis.

6. National Spinal Cord Injury Statistical Center (2019) Spinal cord injury facts and figures at a glance. University of Alabama at Birmingham.

7. DeVivo MJ (2012) Epidemiology of traumatic spinal cord injury: Trends and future implications. Spinal Cord 50(5): 365-372.

8. DeVivo MJ, Black KJ, Stover SL (1993) Causes of death during the first 12 years after spinal cord injury. Archives of Physical Medicine and Rehabilitation 74(3): 248-254.

9. Jain NB, Ayers GD, Peterson EN, et al. (2015) Traumatic spinal cord injury in the United States, 1993-2012. JAMA 313(22): 2236-2243.

10. National Spinal Cord Injury Statistical Center (2015) Spinal cord injury facts and figures at a glance. University of Alabama at Birmingham.

11. Migliorini C, Tonge B, Taleporos G (2008) Spinal cord injury and mental health. Australian \& New Zealand Journal of Psychiatry 42(4): 309-314.

12. Shepherd Center (n.d.) Breathing after SCI. 
13. Goulet J, Richard-Denis A, Thompson C, et al. (2019) Relationships between specific functional abilities and healthrelated quality of life in chronic traumatic spinal cord injury. American Journal of Physical Medicine \& Rehabilitation 98(1): 14-19.

14. Scivoletto G, Galli G, Torre M, et al. (2019) The overlooked outcome measure for spinal cord injury: Use of assistive devices. Frontiers in Neurology 10: 272.

15. Müller R, Peter C, Cieza A, et al. (2012) The role of social support and social skills in people with spinal cord injury-a systematic review of the literature. Spinal Cord 50(2): 94-106.

16. Viemerö V, Krause C (1998) Quality of life in individuals with physical disabilities. Psychotherapy and Psychosomatics 67(6): 317-322.

17. Psarra E, Kleftaras G (2013) Adaptation to physical disabilities: The role of meaning in life and depression. The European Journal of Counselling Psychology 2(1) 79-99.

18. Easton H, Krippner S (1964) Disability, rehabilitation, and existentialism. The Personnel and Guidance Journal 43(3): 230-234.

19. Frankl VE (1967) Logotherapy and existentialism. Psychotherapy: Theory, Research \& Practice 4(3): 138-142.

20. Arvig T (2006) Meaning in life for individuals with physical disabilities. Psychological Reports 98(3): 683-688.

21. Phillips BN, Smedema SM, Fleming AR, et al. (2016) Mediators of disability and hope for people with spinal cord injury. Disability and Rehabilitation 38(17): 1672-1683.

22. Saleeby D (2013) The strengths perspective in social work practice. Pearson: University of Kansas.

23. Rew L (2005) Adolescent health: A multidisciplinary approach to theory, research, and intervention. Sage.

24. Frankl V (1977) Man's search for meaning. New York: A Kangaroo Book. 